\title{
Determination of the Origin for the Dissymmetry Observed between Tensile and Compression Tests on Shape Memory Alloys
}

\author{
E. Patoor, M. El Amrani, A. Eberhardt and M. Berveiller \\ Laboratoire de Physique et Mécanique des Matériaux URA 1215 du CNRS, Institut Supérieur de Génie \\ Mécanique et Productique, Université de Metz, Ile du Saulcy, 57045 Metz cedex, France
}

\begin{abstract}
Experimental observations performed on polycrystalline $\mathrm{Cu}$-based Shape memory alloys exhibit assymmetrical responses for tensile or compressive test. We used a micromechanical point of view to determine the physical origin of this dissymmetry. At first approximation, we assume that the stress field is uniform inside the material and equals to the applied stress. This modelling gives some differences in the transformation slope and in the transformation strain associated to these two loading conditions. Using this approach we established that the volume change associated to the phase transformation exerts no influence upon this phenomenon. It appears that the low symmetry of the martensite is the major physical origin of this assymmetry. Finally, we improve the accuracy of these results using a self-consistent approach to determine the macroscopic behavior from the definition of the local constitutive equations. This modelling is able to determine the internal stress field developed by the phase transition. This approach gives different critical transformation stress and different hysteresis size for tensile or compressive test. Results obtained by this modelling are in good agreement with experimental features observed on $\mathrm{Cu}$-based Shape Memory alloys. Multiaxial loading are then numerically performed and used to determine a macroscopic transformation criterion.
\end{abstract}

\section{INTRODUCTION}

Many experimental recent works have clearly established that the martensitic transformation does not proceed in a symmetrical way in the stress space. Vacher and Lexcellent [1] have observed a very large dissymmetry in the mechanical response for tensile and compressive test on a $\mathrm{Cu}$-Zn-Al Shape Memory Alloy. This result was confirmed by Roumagnac [2] on a $\mathrm{Ni}-\mathrm{Ti}$ alloy. Rogueda [3] investigated biaxial tensile-torsion test on $\mathrm{Cu}-\mathrm{Zn}-\mathrm{Al}$ alloy, and these results do not fit with a Von Mises symmetrical transformation criterion. The design of shape memory devices (for instance with a bending load) imposes to define an assymmetrical transformation criterion.

To obtain such criterion it is necessary to determine at first the physical origin of this phenomenon. A micromechanical approach is applied to this problem. Relative influence of the volume change due to the transformation and crystallographical features are considered using an uniform stress field approximation. Relevant parameters related to this dissymmetry are then determined. A more accurate approach is finally applied to define a transformation surface in the stress space coordinates. The Prager equation is then used to fit this yield surface, this gives a valuable macroscopic transformation criterion.

\section{MICROMECHANICAL MODELLING}

In this section major features associated to the micromechanical approaches used in this study are reviewed, and material parameters are defined.

\subsection{Kinematical aspects}


Due to the microstructure of the martensitic phase (existence of several variants of martensite) the transformation strain field is considered as piecewise uniform. Variants of martensite are characterized by a habit plane normal $\mathbf{n}$ and a direction of transformation $\mathbf{m}$. The transformation strain $\varepsilon^{\mathbf{n}}$ associated to the formation of a variant $\mathrm{n}$ is related to these characteristics and to the amplitude $\mathrm{g}$ of the transformation strain that is equal for all. Using infinitesimal deformation framework and assuming uniform elastic complience tensor $\mathrm{M}$ gives the overall transformation strain $\varepsilon^{\mathbf{T r}}$ as the mean value of the local strain field :

$$
\varepsilon_{\mathrm{ij}}^{\mathrm{Tr}}=\sum_{\mathrm{n}} \varepsilon_{\mathrm{ij}}^{\mathrm{n}} \mathrm{f}^{\mathrm{n}}
$$

where $\mathrm{f}^{\mathrm{n}}$ denotes the volume fraction of each variant. These parameters are choosen as internal variables to describe the microstructural evolution. Physical limitations put these quantities upon kinematical constraints are exerted upon them.

$$
f^{n} \geq 0 \quad \text { and } \quad \sum_{n} f^{n}=f \leq 1
$$

This set of equations define the kinematical aspects associated to the martensitic transformation. They are usefull both for transformation and reorientation mechanisms [4].

\subsection{Thermodynamical potential}

Evolution of strain (1) is obtained from the definition of a thermodynamical potential fonction of the control parameters (applied stress $\Sigma$ and temperature $T$ ) and of internal variables $\mathrm{f}^{\mathrm{n}}$. For an unit reference volume $V$ of parent phase, the complementary free energy $\Psi\left(\Sigma, T, f^{n}\right)$ composed by elastic and chemical contributions is expressed by [4]:

$$
\Psi\left(\Sigma_{i j}, T, f^{n}\right)=\frac{1}{2} \Sigma_{i j} M_{i j k l} \Sigma_{k l}+\Sigma_{i j} \sum_{n} \varepsilon_{i j}^{n} f^{n}-B\left(T-T_{0}\right) f-\frac{1}{2} \sum_{n, m} H^{n m} f^{n} f^{m}
$$

$\mathrm{T}_{0}$ denotes the thermodynamical equilibrium temperature, $\mathrm{H}^{\mathrm{nm}}$ is the interaction matrix related to the incompatibilities in the transformation strain field. In order to put in evidence the microstructural origin of the observed dissymmetry a linear approximation of potential (3) is used at first.

\subsection{Linear optimization}

Evolution of the overall shape memory behavior can be obtained optimizing the thermodynamical potential (3). Due to the existence of kinematical constraints (2) a quadratic constraint optimization must be done. This problem can be simplified using a linear approximation. This leads to ignore the last contribution in potential (3), in that way strain incompatibilities are neglected. Such assumption is equivalent to use an uniform stress approximation. In this framework, despite strong assumptions at the grain level (transformation at constant stress level, only one variant per grain) some interesting information on the influence of the granular structure are obtained [5]. More acurate modelling is realized using a selfconsistent method.

\subsection{Self-consistent resolution}

A local constitutive equation can be derived from the definition of potential (3) [6]

$$
\dot{\varepsilon}_{\mathrm{ij}}^{\mathrm{Tr}}=\sum_{\mathbf{n}} \varepsilon_{\mathrm{ij}}^{\mathrm{n}} \sum_{\mathrm{m}}\left(\mathrm{H}^{\mathrm{nm}}\right)^{-1}\left[\varepsilon_{\mathrm{kl}}^{\mathrm{m}} \dot{\Sigma}_{\mathrm{kl}}-\mathbf{B} \dot{\mathrm{T}}\right]
$$

Such equation characterizes the behavior of a parent phase crystal undergoing a stress-induced martensitic transformation. Occurence of multivariant transformation, as it happens at the grain level inside a polycrystalline material, is taken into account. Relation (4) is used to described the local grain behavior. Intergranular internal stress field arising from the granular structure is computed using a micro-macro transition [4]. We consider the polycrystalline material as an aggregate of grains having homogeneous behavior this leads concentration tensors (that relate local quantities to global one) and local tangent modulus to be piecewise uniform. The overall behavior is then defined from the knowledge of the internal structure evolution. In this framework, intragranular interactions are related to the interaction matrix (compatible and incompatible variants) and intergranular features are obtained from the micro-macro transition. 


\section{NUMERICAL DATA}

The polycrystalline structure is described using 100 grains having different crystallographic orientations. These orientations are randomly chosen to induce no particular texture effect in the material. The grain shape is assumed to be spherical. All these grains are assume to have an identical size.

For each system of alloy, the martensitic transformation is characterized by a set of habit plane normal and transformation direction (Table 1). Due to the symmetry of the parent phase lattice, 24 variants of the same martensitic phase can be produced. These variants are determined from the parameters given in table 1 (Table 2). In this paper, $\mathrm{Cu}-\mathrm{Zn}-\mathrm{Al}$ and $\mathrm{Ni}-\mathrm{Ti}$ shape memory alloys are studied. For $\mathrm{Cu}-\mathrm{Zn}-\mathrm{Al}$ alloys four type of characteristics are used. The first one determined by Saburi et al. [7] gives a negative volume change associated to the transformation and the second one due to De Vos et al. [8] gives a positive one. In order to test the influence of this volume change on the behavior dissymmetry a transformation without any volume change is also used. Such transformation is numerically obtained by El Amrani [9] projecting the direction of transformation on the habit plane.These three sets of parameters are both near [ $\left.\begin{array}{llll}2 & 11 & 12\end{array}\right]$ direction thus they can be approximated by the [0 11 1] one.

In $\mathrm{Cu}-\mathrm{Zn}-\mathrm{Al}$ Shape memory alloy tensile test experiments performed on single crystal specimen at different temperature levels [11] give $\mathrm{B}$ around $0.23 \mathrm{MPa} . \mathrm{K}^{-1}$.

\begin{tabular}{|c|c|c|c|c|c|c|c|c|}
\hline & \multicolumn{3}{|c|}{ Habit plane normal } & \multicolumn{3}{|c|}{ Transformation direction } & & \\
\hline & $\mathrm{n} 1$ & $\mathrm{n} 2$ & n3 & $\mathrm{m} 1$ & $\mathrm{~m} 2$ & $\mathrm{~m} 3$ & $\mathrm{~g}$ & $\Delta \mathrm{V} / \mathrm{V}$ \\
\hline $\mathrm{Cu} \mathrm{Zn} \mathrm{Al} \mathrm{[7]}$ & 0.1999 & 0.6804 & 0.7050 & 0.1817 & -0.7457 & 0.6411 & 0.1866 & -0.00356 \\
\hline $\mathrm{Cu} \mathrm{Zn} \mathrm{Al} \mathrm{[8]}$ & 0.1817 & 0.669 & 0.721 & 0.165 & -0.737 & 0.655 & 0.23 & +0.00211 \\
\hline $\mathrm{Cu} \mathrm{Zn} \mathrm{Al}[9]$ & 0.1817 & 0.669 & 0.721 & 0.1634 & -0.7435 & 0.6487 & 0.23 & 0.0 \\
\hline $\mathrm{Cu} \mathrm{Zn} \mathrm{Al} *$ & 0.0 & 1.0 & 1.0 & 0.0 & -1.0 & 1.0 & 0.23 & 0.0 \\
\hline NiTi [10] & -0.8889 & 0.2152 & 0.4044 & 0.4345 & 0.7543 & 0.4874 & 0.1308 & -0.00341 \\
\hline
\end{tabular}

Table 1. Crystallographical characteristics for the martensitic transformation in $\mathrm{Cu}-\mathrm{Zn}-\mathrm{Al}$ and $\mathrm{Ni}-\mathrm{Ti}$ shape memory alloys.

\begin{tabular}{|c|c|c|c|c|c|c|}
\hline 1 & $\mathrm{n} 1$ & $\mathrm{n} 2$ & $\mathrm{n} 3$ & $\mathrm{~m} 1$ & $\mathrm{~m} 2$ & $\mathrm{~m} 3$ \\
\hline 2 & $-\mathrm{n} 1$ & $-\mathrm{n} 3$ & $-\mathrm{n} 2$ & $-\mathrm{m} 1$ & $-\mathrm{m} 3$ & $-\mathrm{m} 2$ \\
\hline 3 & $\mathrm{n} 1$ & $-\mathrm{n} 2$ & $-\mathrm{n} 3$ & $\mathrm{~m} 1$ & $-\mathrm{m} 2$ & $-\mathrm{m} 3$ \\
\hline 4 & $-\mathrm{n} 1$ & $\mathrm{n} 3$ & $\mathrm{n} 2$ & $-\mathrm{m} 1$ & $\mathrm{~m} 3$ & $\mathrm{~m} 2$ \\
\hline 5 & $-\mathrm{n} 2$ & $\mathrm{n} 1$ & $\mathrm{n} 3$ & $-\mathrm{m} 2$ & $\mathrm{~m} 1$ & $\mathrm{~m} 3$ \\
\hline 6 & $\mathrm{n} 3$ & $-\mathrm{n} 1$ & $-\mathrm{n} 2$ & $\mathrm{~m} 3$ & $-\mathrm{m} 1$ & $-\mathrm{m} 2$ \\
\hline 7 & $\mathrm{n} 2$ & $\mathrm{n} 1$ & $-\mathrm{n} 3$ & $\mathrm{~m} 2$ & $\mathrm{~m} 1$ & $-\mathrm{m} 3$ \\
\hline 8 & $-\mathrm{n} 3$ & $-\mathrm{n} 1$ & $\mathrm{n} 2$ & $-\mathrm{m} 3$ & $-\mathrm{m} 1$ & $\mathrm{~m} 2$ \\
\hline 9 & $-\mathrm{n} 1$ & $\mathrm{n} 2$ & $-\mathrm{n} 3$ & $-\mathrm{m} 1$ & $\mathrm{~m} 2$ & $-\mathrm{m} 3$ \\
\hline 10 & $\mathrm{n} 1$ & $-\mathrm{n} 3$ & $\mathrm{n} 2$ & $\mathrm{~m} 1$ & $-\mathrm{m} 3$ & $\mathrm{~m} 2$ \\
\hline 11 & $-\mathrm{n} 1$ & $-\mathrm{n} 2$ & $\mathrm{n} 3$ & $-\mathrm{m} 1$ & $-\mathrm{m} 2$ & $\mathrm{~m} 3$ \\
\hline 12 & $\mathrm{n} 1$ & $\mathrm{n} 3$ & $-\mathrm{n} 2$ & $\mathrm{~m} 1$ & $\mathrm{~m} 3$ & $-\mathrm{m} 2$ \\
\hline
\end{tabular}

\begin{tabular}{|c|c|c|c|c|c|c|}
\hline 13 & $\mathrm{n} 3$ & $\mathrm{n} 1$ & $\mathrm{n} 2$ & $\mathrm{~m} 3$ & $\mathrm{~m} 1$ & $\mathrm{~m} 2$ \\
\hline 14 & $-\mathrm{n} 2$ & $-\mathrm{n} 1$ & $-\mathrm{n} 3$ & $-\mathrm{m} 2$ & $-\mathrm{m} 1$ & $-\mathrm{m} 3$ \\
\hline 15 & $-\mathrm{n} 3$ & $\mathrm{n} 1$ & $-\mathrm{n} 2$ & $-\mathrm{m} 3$ & $\mathrm{~m} 1$ & $-\mathrm{m} 2$ \\
\hline 16 & $\mathrm{n} 2$ & $-\mathrm{n} 1$ & $\mathrm{n} 3$ & $\mathrm{~m} 2$ & $-\mathrm{m} 1$ & $\mathrm{~m} 3$ \\
\hline 17 & $\mathrm{n} 2$ & $-\mathrm{n} 3$ & $-\mathrm{n} 1$ & $\mathrm{~m} 2$ & $-\mathrm{m} 3$ & $-\mathrm{m} 1$ \\
\hline 18 & $-\mathrm{n} 3$ & $\mathrm{n} 2$ & $\mathrm{n} 1$ & $-\mathrm{m} 3$ & $\mathrm{~m} 2$ & $\mathrm{~m} 1$ \\
\hline 19 & $-\mathrm{n} 2$ & $\mathrm{n} 3$ & $-\mathrm{n} 1$ & $-\mathrm{m} 2$ & $\mathrm{~m} 3$ & $-\mathrm{m} 1$ \\
\hline 20 & $\mathrm{n} 3$ & $-\mathrm{n} 2$ & $\mathrm{n} 1$ & $\mathrm{~m} 3$ & $-\mathrm{m} 2$ & $\mathrm{~m} 1$ \\
\hline 21 & $-\mathrm{n} 3$ & $-\mathrm{n} 2$ & $-\mathrm{n} 1$ & $-\mathrm{m} 3$ & $-\mathrm{m} 2$ & $-\mathrm{m} 1$ \\
\hline 22 & $\mathrm{n} 2$ & $\mathrm{n} 3$ & $\mathrm{n} 1$ & $\mathrm{~m} 2$ & $\mathrm{~m} 3$ & $\mathrm{~m} 1$ \\
\hline 23 & $\mathrm{n} 3$ & $\mathrm{n} 2$ & $-\mathrm{n} 1$ & $\mathrm{~m} 3$ & $\mathrm{~m} 2$ & $-\mathrm{m} 1$ \\
\hline 24 & $-\mathrm{n} 2$ & $-\mathrm{n} 3$ & $\mathrm{n} 1$ & $-\mathrm{m} 2$ & $-\mathrm{m} 3$ & $\mathrm{~m} 1$ \\
\hline
\end{tabular}

Table 2. Habit plane normal and transformation direction for the 24 martensitic variants, habit plane normal and direction of transformation come from table 1.

\section{DISCUSSION}

Polycrystalline superelastic behavior is determined for a $\mathrm{Cu}-\mathrm{Zn}-\mathrm{Al}$ alloy using the linear optimization scheme with $\left(\mathrm{T}_{0}-\mathrm{M}_{\mathrm{S}}\right)$ equals to 50 Kelvin. Tensile and compressive tests are computed in such way. Despite strong assumptions used in this framework, numerical results present a large dissymmetry between these two loading conditions as expected from experimental observations [1-3]. Using the different cristallographical data given for this kind of alloy in table 1, it is established that the volum echange has no significant influence on the macroscopic response. Computations give the same result using a negative volume change, a positive one, or for a transformation without any volume change at all (figures la., $1 \mathrm{~b}$ and 1c). Thus this characteristic is not the physical origin of the observed dissymmetry. But an identical

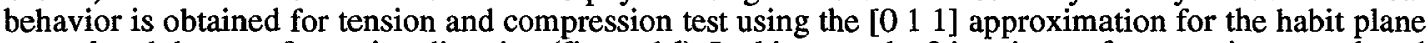
normal and the transformation direction (figure 1d). In this case, the 24 variants of martensite are reduced to 6 due to the high symmetry of these directions. One can conclude that the low symmetry of the martensitic phase play a major role in the dissymmetry of the mechanical response in the stress space. 


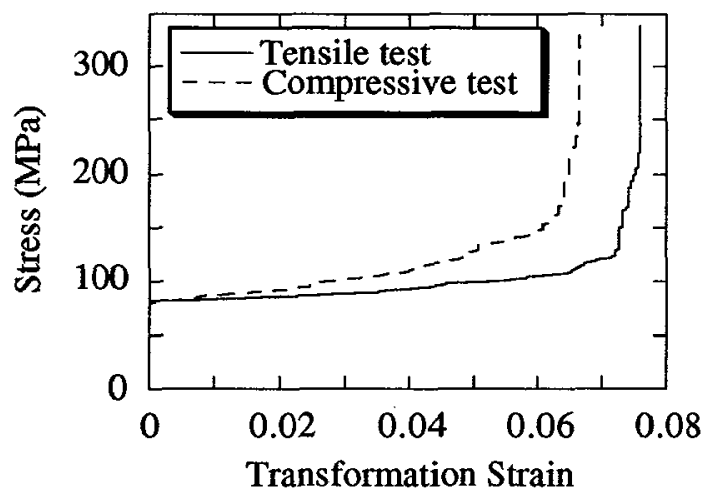

a

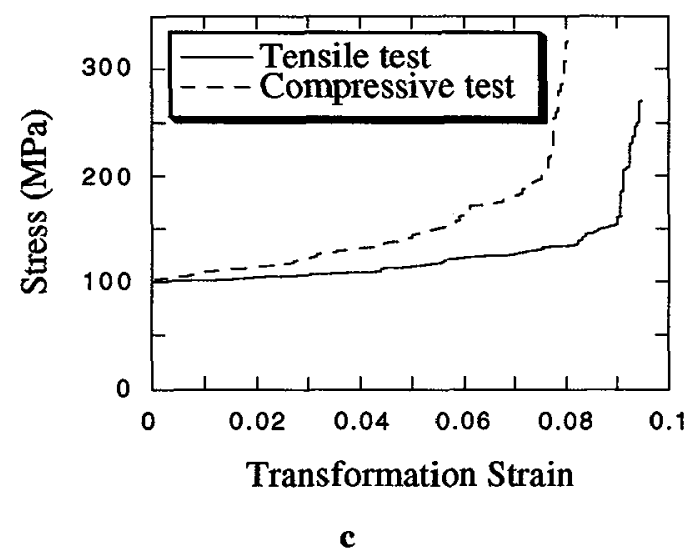

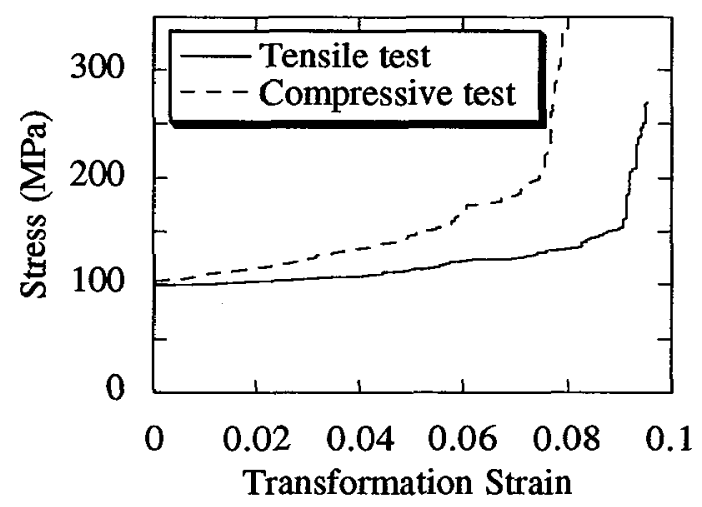

b

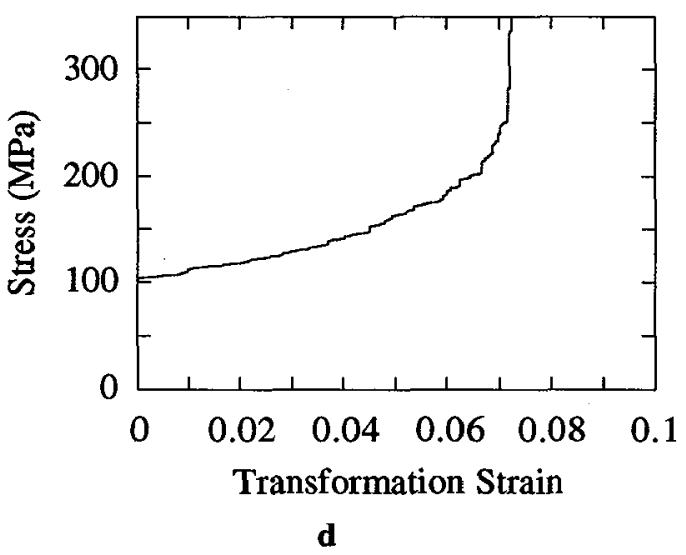

Figure 1 : Tensile and compressive tests computed using a linear optimization framework for $\mathrm{Cu} \mathrm{Zn} \mathrm{Al}$ alloys : a/ with $\Delta \mathrm{V}<0 ; \mathrm{b} /$ with $\Delta \mathrm{V}>0 ; \mathrm{c} /$ with $\Delta \mathrm{V}=0 ; \mathrm{d} / \mathrm{using}$ the [ $\left[\begin{array}{lll}0 & 1 & 1\end{array}\right]$ approximation.

The maximum resolved shear stress factor is determined for various orientations in tensile and compressive testing conditions. This gives additional informations (figure 2). In order to show the orientation dependance of this factor is function of the loading condition, it is drawn in the stereographic triangle for tensile and compressive tests. This is done for $\mathrm{Cu}-\mathrm{Zn}-\mathrm{Al}$ and $\mathrm{Ni}-\mathrm{Ti}$ alloys. Results obtained in tension are in accordance with previous determination for the transformation strain performed on single crystals of these alloys [12-13]. A large dissymmetry is observed in both cases between the orientation dependance for the two loading conditions used. Two physical phenomena contribute to the observed macroscopic behavior. The first one is the low symmetry of the martensitic phase, the second one is associated to the pollycrystalline structure. Figure 2 shows that the size of the domain of well oriented positions (maximum resolved shear stress factor greater than 0.40 for instance) differs with the loading even for a non textured material.

The uniform stress assumption successfully deals with the origin of the assymmetrical aspect of the superelastic behavior. But the strain level obtained is too large. This can be improved using a more accurate micro-macro transition scheme. On $\mathrm{Cu}-\mathrm{Zn}-\mathrm{Al}$ alloy Vacher and Lexcellent [1] have observed that the critical transformation stress, the transformation slope and the hysteresis loop are larger in compressive test than in tensile one. These tendencies are numerically obtained using a self consistent resolution scheme [4] (figure 3) without any additional assumption keeping an isotropic crystallographical texture. Applications to other loading conditions define an assymmetrical transformation surface (figure 4). It can be noticed that the first bisector line of this computed surface is an axis of symmetry. This last point is in aagreement with shear test experiments performed on Ni-Ti alloy by Manach [14].

Such surface is very far from the Von Mises criterion. 


\section{$-111$}

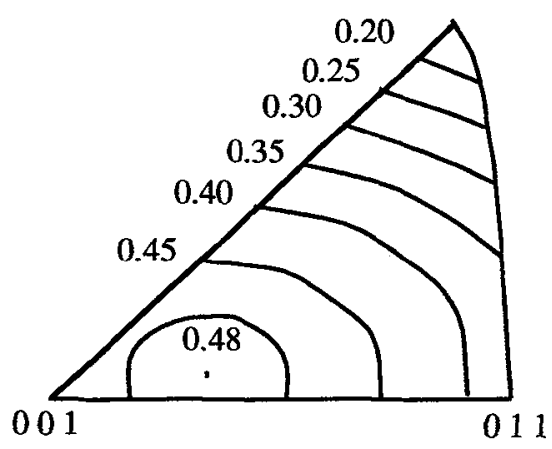

$\mathbf{a}$
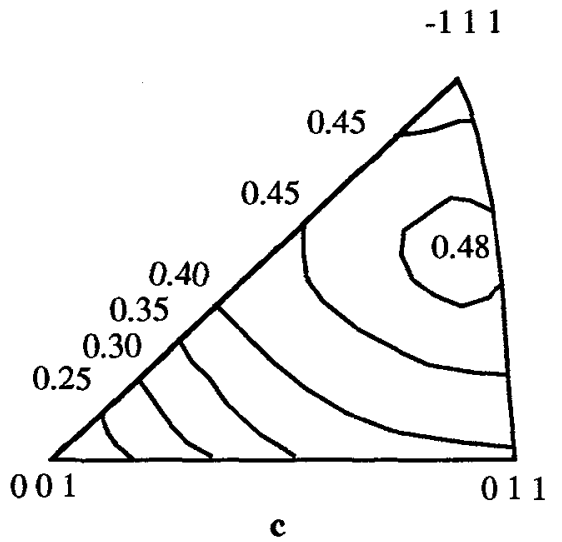

$-111$

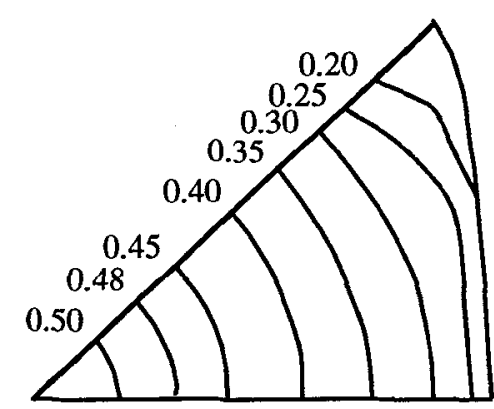

001

b

\section{$-111$}

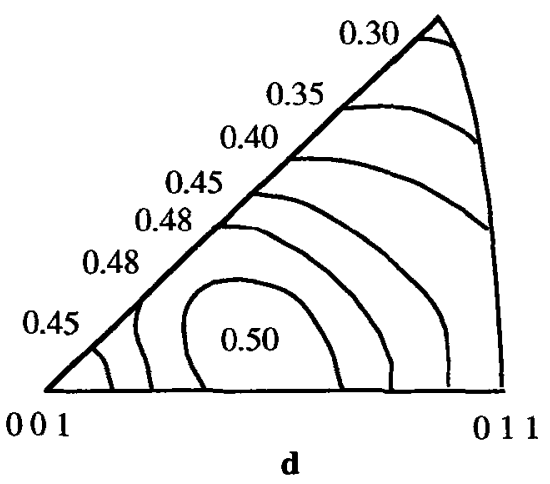

Figure 2 : Resolved shear stress factor computed for uniaxial tensile (a and c) and compressive (b and $d$ ) test condition for $\mathrm{Cu} \mathrm{Zn} \mathrm{Al} \mathrm{(a} \mathrm{and} \mathbf{b})$ and $\mathrm{Ni} \mathrm{Ti}(\mathbf{c}$ and $\mathbf{d})$ shape memory alloys

\section{TRANSFORMATION CRITERION}

Phenomenological considerations on this transformation surface allow to determine a macroscopic transformation criterion. As the material is considered as an isotropic medium such criterion can be expressed using the scalar invariants of the stress tensor. In shape memory alloys the hydrostatic pressure has a very little influence. Thus the second and the third scalar invariant of the deviatoric stress (resp. $\mathrm{J}_{2}$ and $\mathrm{J}_{3}$ ) can be used alone. The simpler form of such expression is obtained from the Prager equation :

$$
\mathrm{F}\left(\mathrm{J}_{2}, \mathrm{~J}_{3}, \varepsilon^{\mathrm{Tr}}, \mathrm{T}\right)=\mathrm{J}_{2}\left[1+\mathrm{b} \frac{\mathrm{J}_{3}}{\mathrm{~J}_{2}^{3 / 2}}\right]-\mathrm{K}^{2}\left(\varepsilon^{\mathrm{Tr}}, \mathrm{T}\right)=0
$$

Taking b equals to zero in this function turns it into the Von Mises criterion. Due to the thermomechanical characteristics of the shape memory behavior, criterion (5) must be a function of the temperature. By analogy with plasticity, the inelastic strain $\varepsilon^{\mathrm{Tr}}$ is chosen as hardening parameter. Identification with tensile and compressive tests gives the following expressions for parameter $b$ and function $K\left(\varepsilon^{T r}, T\right)$.

$$
\mathrm{b}=\frac{\sqrt{27}}{2} \frac{\sigma_{\mathrm{c}}^{2}-\sigma_{\mathrm{t}}^{2}}{\sigma_{\mathrm{c}}^{2}+\sigma_{\mathrm{t}}^{2}} \quad \mathrm{~K}^{2}\left(\varepsilon^{\mathrm{Tr}}, \mathrm{T}\right)=\frac{\sigma_{\mathrm{t}}}{\sqrt{3}} \sqrt{1+\frac{2 \mathrm{~b}}{\sqrt{27}}}
$$

Loading surface obtains in that way shows a very good accordance with the micro-macro determination (figure 4). This assymmetrical transformation criterion can now be applied to determine an analytical 


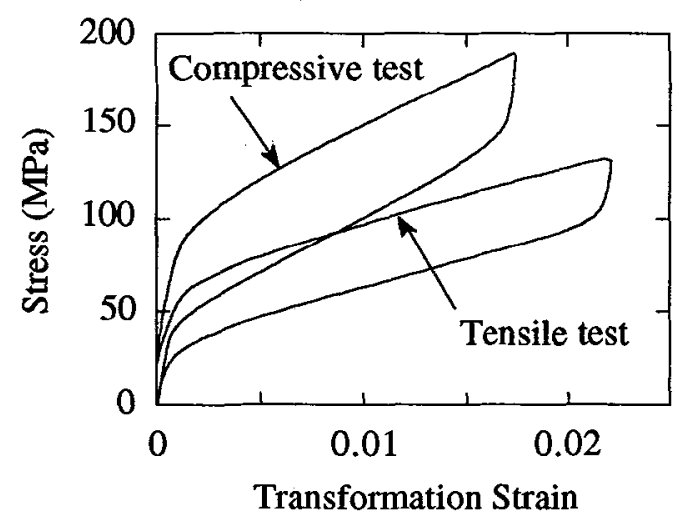

Figure 3: Dissymmetry obtained for tensile and compressive uniaxial test using a self consistent scheme [4].

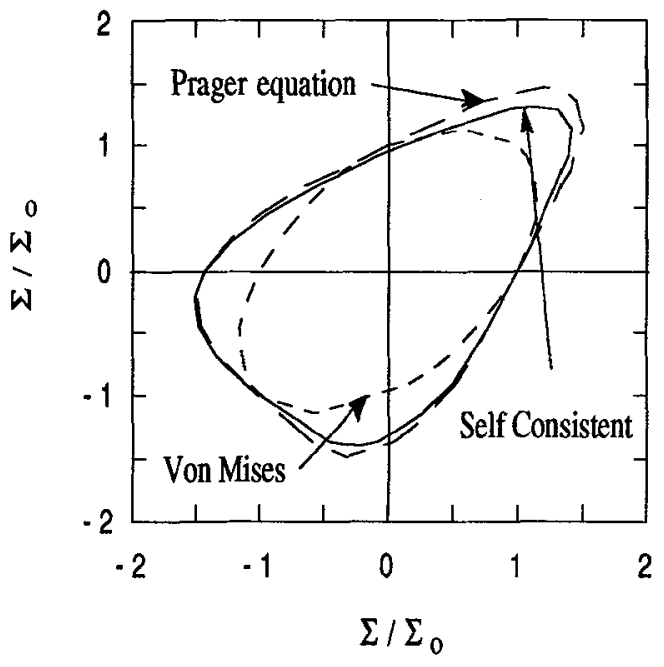

Figure 4: Transformation surface determined by El Amrani using a self consistent model. Comparison with the Von Mises criterion and the Prager equation [9]

behavior law very useful for structure calculation [15]. Such equation is derived using the normality rule. Very good results are thus obtained for superelastic beam in flexure condition by Gillet et al. [16].

\section{CONCLUSION}

The physical origin of the dissymmetry of the polycristalline superelastic behavior in the stress space is established using a micromechanical point of view. Two features are at the origin of this phenomenon. The first one is the low symmetry of the martensitic phase, the second one, associated to the polycrystalline structure, is that the domain of well oriented positions depends on the loading condition. An accurate description of the macroscopic behavior is obtained using a self consistent approach. This framework allows to determine an assymmetrical macroscopic transformation criterion and its associated flow rule. These points are on first importance for engineering applications and are now in development.

\section{References}

[1] Vacher P. and Lexcellent. C, Proccedings, Mechanical behaviour of materials VI, M. JONO et al. ed., (Pergamon Press, 1991) pp. 231-236.

[2] Roumagnac P., Thesis, Université Technologique de Compiegne (1993), France.

[3] Rogueda C., Thesis, Université de Franche Comte, Besançon (1993), France.

[4] Patoor E., Eberhardt A. and Berveiller M., Pitman Research Notes in Mathematics Series, 296 (1993) 38-54.

[5] Patoor E., Bensalah M.O., Eberhardt A. and Berveiller M., Rev. Met., Decembre 1993, 1587-1592

[6] Patoor E., Eberhardt A. and Berveiller M., this conf.

[7] Saburi T. and Wayman C.W., Acta Metall., 27 (1979) 979.

[8] De Vos J., Aernoudt E. and Delaey L., Z. Metallkde, 69 (1978) 438-444.

[9] El Amrani M., Thesis, Université de Metz (1994), France.

[10] Okamoto K., Ichinose S., Morii K., Otsuka K. and Shimizu K., Acta Metall., 34 (1986) 2065.

[11] Patoor E., Eberhardt A. and Berveiller M., Arch. Mech., 40 (1988) 775-794.

[12] Otsuka K., Wayman C.W., Naikai K., Sakamoto H. and Shimizu K., Acta Metall., 24 (1976) 207 226.

[13] Myazaki S., Kimura S., Otsuka K. and Suzuki, Y., Scripta Met., 18 (1984) 883-888.

[14] Manach P. Y., Thesis, Institut National Polytechnique de Grenoble (1992), France.

[15] Gillet, Y., Patoor, E. and Berveiller, M., this conf.

[16] Gillet, Y., Patoor, E. and Berveiller, M., 1994, Proccedings, SMST' 94, Asilomar, C.A.,USA. 